\title{
Anomalous Sub Scapulo- Suprascapular Arterial Trunk - A Case Report
}

\author{
Ishwar Basavantappa. Bagoji ${ }^{1}$, Shankarappa Doddappa. Desai. M.S. ${ }^{2}$, \\ Gavishiddappa A. Hadimani ${ }^{3}$, Bhimsetty S. Patil ${ }^{4}$. \\ ${ }^{4}$ M.Sc. Lecturer, ${ }^{3}$ Professor\& HOD, \\ Dept. Of Anatomy, Sri B M Patil Medical College, BLDE University Bijapur-586103 Karnataka, India
}

\begin{abstract}
An unusual origin of sub scapulo suprascapular arterial trunk was observed in one of the nearly old male embalmed cadaver during routine dissection classes for MBBS students. The sub scapulo supra scapular arterial trunk was seen to emerge from the $1^{\text {st }}$ part of axillary artery on the right side of cadaver. While on left side axillary arterial branches were normal origin. The anomalous sub scapulo supra scapular arterial trunk was courses obliquely between musculocutaneus nerve and median nerve. Total length measured $4.2 \mathrm{cms}$, and terminate into three branches, ventral \& dorsal branches to subscapularis muscle and supra scapular branch. The supra scapular branch accompanied by supra scapular nerve, together passed beneath the superior transverse ligament. It then supplied the supra spinatus muscle. And finally took part in the anastomosis around the scapula. The anatomical knowledge of the sub scapular \& supra scapular artery is of crucial importance for neurosurgeons and arthropedicians. The improved knowledge would allow more accurate diagnostic interpretations and surgical treatment.
\end{abstract}

Key words: Axillary artery, Sub scapulo-supra scapular arterial trunk, Superior transverse ligament.

\section{Introduction:}

The axillary artery, a continuation of the subclavian artery, begins at the outer border of the first rib, and end normally at the inferior border of teres major muscle where onwards it continues as the brachial artery. Pectoralis minor muscle crosses it and so divides it into three parts which are proximal, posterior and distal to the muscle. Conventionally, the proximal part (first part) gives superior thoracic artery, the posterior part (second part) gives thoraco-acromial and lateral thoracic arteries and distal part (third part) gives sub scapular artery, anterior and posterior circumflex humeral arteries (Standring et al., 2005). Sub scapular artery is the largest branch from the third part of axillary artery, supplies the subscapularis muscle. Supra scapular artery is usually branch from the thyrocervical trunk of the sub clavian artery, courses above the superior transverse ligament, supply the supra spinatus muscle. And finally complete the anastomosis around the scapula.

\section{Case report:}

During routine dissection an unusual unilateral origin of sub scapulo-supra scapular trunk was observed in nearly old male embalmed cadaver, in the department of anatomy Sri B M Patil medical college Bijapur. The anomalous origin of arterial trunk has seen to be arising from first part of the axillary artery on right upper limb. On left side axillary arterial course and branches were normal. And the variant artery was coursed obliquely below the musculocutaneus nerve and above the median nerve. Near the sub scapular muscle, the arterial trunk was terminates into three branches (fig.1) among the three branches two branch were supplying ventral and dorsal surfaces of the subscapularis muscle. And the third branch was courses towards the superior transverse ligament as supra scapular artery. The total length of the artery was measured about $4.2 \mathrm{~cm}$ (origin from axillary artery, up to its branches). The supra scapular artery was courses along with the supra scapular nerve. Finally both the supra scapular artery and nerve courses beneath the transverse scapular ligament (fig-2), and supplied the supra spinatus muscle. And later it passes to the infra spinatus fossa through the sphenoglynoid notch, and took part in the anastomosis around the scapula.

\section{Discussion:}

Anatomical variations in the major arteries of the upper limb have been reported. It is not uncommon to find variations in the branching pattern of axillary artery. Many of its branches may arise by a common trunk or a branch of the named artery may arise separately (Holinshed, 1958).

Saeed et al. (2002) reports, a bilateral common sub scapular-circumflex humeral trunk $(3.8 \%)$ emerging from the 3rd part of the axillary artery (branching into the circumflex humeral and thoracodorsal arteries) and a bilateral thoraco-humeral trunk arising from the 2nd part of the axillary artery (1.9\%) and branching into the lateral thoracic, circumflex humeral, sub scapular and thoracodorsal arteries. 
Syad Rehan daimi et al. (2010) reports, unilateral origin of sub scapular artery from second part of axillary artery Venieratos \& Lolis (2001) shows common sub scapular trunk gave origin to circumflex scapular, thoracodorsal, anterior and posterior circumflex humeral, profunda brachii and ulnar collateral arteries.

In another report by Samuel et al. (2006) the third part of the axillary artery gave a common arterial trunk, which further gave anterior and posterior circumflex humeral, sub scapular, radial collateral, middle collateral and superior ulnar collateral arteries with absence of profunda brachii artery.

Saralaya,v. et al. (2008) reported sub scapular common trunk and its thoraco acromial branch provides acromial, clavicular and deltoid branches but not the pectoral branch was given separately by the sub scapular trunk Mishra et al. (2003) reported variant origin of supra scapular artery from subclavian internal thoracic artery and from axillary artery.

Our present report differs from this earlier report in branching pattern as well as course of these branches.Such anomalous branching pattern may represent persisting branches of the capillary plexus of the developing limb buds and their unusual course may be a cause for concern to the vascular radiologists and surgeons and may lead to complications in surgeries involving the axilla and the pectoral regions.

\section{Conclusion:}

The clinical importance of the described arterial variation is of utmost significance for surgeons,cardiologists and vascular specialists. It is specially relevant in cases of arteriovenous fistulae, aneurysms and abcess drainage in region of axilla, arm and cubital fossa. In angiographic studies preceeding coronary artery bypass surgery such aberrant anatomy should be timely confirmed to reduce the incidence of iatrogenic injuries .Branches of axillary and brachial artery variations are relevant in shoulder, arm and forearm sugery, in fractures \& dislocations. Awareness of such abnormal branches of axillary vasculature is crucial in use of superficial brachial artery flap in plastic surgery and protection of axillary artery in breast cancer surgery. Undoubtedly, such variations are important for diagnostic evaluation and surgical management of vascular diseases and injuries.

\section{References:}

[1] Standring, S.; Johnson, D.; Ellis, H. \& Collins, P. Gray's Anatomy. 39th Ed. Churchill Livingstone, London, 2005.p.856.

[2] Holinshed, W.H. Cornelius Rosse text book of Anatomy for Surgeons Vol. 1, Head and Neck. In: the neck. $4^{\text {th }}$ edition: Harper and Row publishers, Philadelphia. pp. 454-457. (1982).

[3] Saeed, M.; Rufai, A. A.; Elsayed, S. E. \& Sadiq, M. S.Variations in the subclavian-axillary arterial system.Saudi Med. J., 22(2):206$12,2002$.

[4] Syed rehan Daimi, Abu Ubaida Siddiqui, Rajendra Namdeo Wabale. Variations in the branching pattern of axillary artery with high origin of radial artery, International Journal of Anatomical Variations (2010) 3: 76-77

[5] Venieratos, D. \& Lolis, E. D. Abnormal ramification of the axillary artery: sub-scapular common trunk. Morphologie., 85(270):23-4, 2001.

[6] Samuel, V. P.; Vollala, V. R.; Nayak, S.; Rao, M.; Bolla, S.R. \& Pammidi, N. A rare variation in the branching pattern of the axillary artery. Indian J. Plast. Surg.,39:222-3, 2006

[7] Saralaya, v.; joy, t.; madhyastha, s.; vadgaonkar, r. \& saralaya, s. Abnormal branching of the axillary artery: subscapular common trunk. A case report. Int. J. Morphol., 26(4):963-966, 2008

[8] Mishra S, Ajmani ML. Anomalous origin of supra scapular artery- a case report. J Anat Soc India.2003;52:

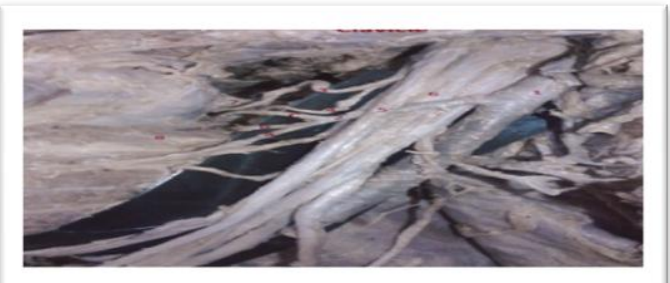

Fig-1. 1- Axillary artery, 2- common sub scapulo supra scapular trunk, 2a- Ventral branch, 2b- Dorsal branches of subscapular artery 2c- Suprascapular artery, 3-Supra scapular nerve 4-And its Subscapular branch, 5-Musculocutaneus nerve, 6-median nerve, 7-Superior transverse ligament 8- Subscapularis muscle

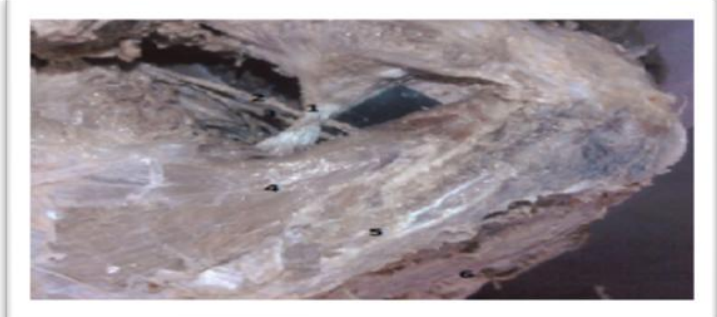

Fig- 2. 1-Superior transverse ligament, 2-Suprascapular nerve,3-Suprascapular artery, 4-Supraspinatus muscle, 5-Spine of scapula, 6-Infraspinatus muscle 